\title{
Crítica y reformismo dieciochescos. Algunos textos sobre Filipinas
}

María Fernanda García de los Arcos

Universidad Autónoma Metropolitana-Iztapalapa México, D. F.

\begin{abstract}
Al igual que en España y América, en las Filipinas de la segunda mitad del siglo XVIII se produjeron escritos en los que se analizaba la realidad del archipiélago, las causas de sus problemas y las posibles soluciones para superarlos. Algunos de estos textos permanecen inéditos. Así ocurre con los tres que se estudian en este artículo, en el que se hace una valoración comparativa sobre sus posibilidades como fuentes para apreciar la situación general de las Islas en ese período y las ideas que tenía la élite dirigente sobre ella, especialmente en tres aspectos: la personalidad colectiva de los nativos; las formas de explotación colonial y sus repercusiones sobre la mayoría de la población y las causas que originaban lo que entonces llamaban "el atraso" de aquellos territorios.
\end{abstract}

Los ánimos renovadores —ilustrados o no- que recorrían Europa y las colonias americanas en el siglo XVIII tuvieron eco en Filipinas, lo cual no es ninguna revelación, pues felizmente no faltan en la actualidad libros y artículos en los que ya ha sido planteado este fenómeno. Pero es también cierto que, al igual que tantas otras cosas referentes a la historia del dominio español sobre el Archipiélago, la difusión de las investigaciones no suele rebasar los estrechos círculos de los especialistas. Desde luego, aunque se disponga de buenas contribuciones, se está muy lejos de poder decir que el tema haya sido agotado o suficientemente estudiado. Los archivos guardan una enorme riqueza documental que puede arrojar muchas luces sobre las condiciones de vida que experimentaban las clases populares, los problemas que éstas afrontaban de cara a las realidades impuestas por la colonización y la imagen que los integrantes de las élites tenían de las tierras, mares y gente del territorio.

Las fuentes en las que se basa este estudio se hallan en el Archivo General de Indias de Sevilla y se refieren a un momento de la historia de Filipinas en que todavía existía el gran Imperio español en América. Aquel archipiélago había sido siempre considerado como parte integrante de él, pese a la lejanía y a otras circunstancias y hubo un deseo de que se asemejara más a otras colonias. Tal cosa sólo se logró en parte, debido sin duda a la vitalidad de la cultura filipina, pero también a otros factores, algunos de ellos derivados de la misma política estatal. 
En la segunda mitad del siglo XVIII se implantó una serie de reformas en el país. Algunas no llegaron a ser más que proyectos, otras no cristalizaron realmente en cambios importantes sino hasta el siglo XIX. Sin embargo constituyeron un intento significativo que, por una parte, correspondía a la planificación general reformadora que afectó a todo el imperio español y, por otra parte, conllevaba planes creados específicamente para el caso filipino. Entre las reformas se encontraron modificaciones al aparato militar, el comercio directo entre Filipinas y España, la apertura del puerto de Manila al comercio internacional, la creación del Consulado de Manila, la implantación del sistema de Intendencias, el monopolio del tabaco, el estanco del vino de nipa, el intento de secularización de los curatos... ${ }^{1}$

Todos estos procesos generaron una abundante producción de documentos en los que se plasmaron análisis, opiniones y proyectos. ${ }^{2}$ Los que se presentan aquí están relacionados con las reformas, aunque no ofrecen precisamente una imagen idílica de ellas. El primero de estos escritos fue elaborado por Pedro Vértiz, oriundo del sur de España, que viajó expresamente a Filipinas para ocupar el puesto de intendente de la Provincia de Cebú. Al parecer era un hombre ilustrado. Su estancia en el archipiélago no fue larga: llegó a Manila en 1787 y se trasladó a las islas Visayas donde desembarcó en junio de 1788. Pero las tensiones en que se vio envuelta la implantación del sistema de Intendencias en las islas, hizo que este régimen fuera suprimido, por lo que Vértiz regresó a Manila en septiembre del mismo año y fue seguramente allí donde redactó el texto que se va a comentar, titulado Relación del estado de las Islas Visayas y de todas las Filipinas... ${ }^{3}$ El segundo documento está fechado unos años más tarde en

1 Díaz-Trechuelo Spínola, M. ${ }^{a}$ Lourdes: La Real Compañía de Filipinas. Sevilla, 1965; Rodríguez Baena, Ma Luisa: La Sociedad Económica de Amigos del País de Manila en el siglo XVIII, Sevilla, 1966; Ortiz de la Tabla Ducasse, Javier: El Marqués de Ovando Gobernador de Filipinas (1750-1754), Sevilla, 1974; Martín Palma, M. L.: El Consulado de Manila. Granada, 1979; García de

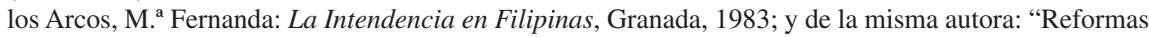
y resistencias en las Filipinas de la segunda mitad del siglo XVIII”. Iztapalapa, núm. 24, México, 1991, págs. 93-108.

2 Díaz-Trechuelo S., M M $^{\mathrm{a}}$ L.: Historia económica de Filipinas en la segunda mitad del siglo XVIII. Manila, Cuadernos del Centro Cultural, 1978; de la misma autora: "Philippine Economic Development Plans". Philippine Studies, T. XII, nº 2, Manila, 1964, págs. 203-231.

3 Archivo General de Indias (en adelante, AGI), Ultramar, 613. Relación del Estado de las Indias Visayas y de todas las Filipinas, de los males que padecen y de los medios que para su restauración propone a la Real Católica Majestad del Señor Don Carlos Tercero por medio de su Secretario de Estado y del Despacho Universal de Guerra, Comercio y Navegación de Indias, El Excmo. Señor Baylio Don F. Antonio Valdés y Bazán, El Intendente propietario que ha sido de la Provincia de Cebú Don Pedro Vértiz y Castejón. Vértiz al rey. Manila, 14 de diciembre de 1788. 
1791. Su autor, Santiago de Salaberrias, fue alcalde mayor (una especie de gobernador de provincia) en IloIlo durante cinco años. ${ }^{4} \mathrm{El}$ tercer escrito es tan rico como el de Vértiz y se llama Observaciones sobre el estado político y económico de Filipinas. ${ }^{5}$ Es anónimo y, según todos los indicios, escrito por un personaje relevante. Tampoco tiene fecha, pero el legajo en que se encuentra contiene papeles del período comprendido entre 1788 y 1814. Según se deduce por el contenido del texto es anterior a la supresión del tradicional sistema del galeón transpacífico (la cual tuvo lugar legalmente en 1813, realizándose en 1815 el último viaje) y posterior a la apertura del puerto de Manila por tres años (1790).

La importancia de estos tres escritos radica precisamente en servir de refuerzo y de comparación a otras opiniones vertidas por colonialistas españoles en ese momento tan especial en la historia del Imperio. El primero y el último documentos tienen pretensiones de hacer una reflexión sobre la globalidad de los problemas, siempre desde la óptica de personas ligadas de un modo u otro al poder, y dar soluciones para ellos. El texto de Salaberrias es más modesto. El hizo una descripción y una crítica que no pretendió aludir más que a la isla de Panay. Pero es conveniente incluirlo en este escrito porque se refiere a una parte de las islas Visayas, región de la que los otros autores también se ocupan y que alcanza un protagonismo especial en los tres textos. En este sentido, el contraste es evidente con otros muchos documentos de la época, que se centran principalmente en Manila y en las áreas vecinas a la capital. Otra razón para incluirlo es el haber sido Salaberrias alcalde mayor, uno de los funcionarios que suscitaron críticas más generalizadas.

Las tres son fuentes cualitativas, muy dieciochescas en lo que atañe a los escritos de Vértiz y a las Observaciones... Corresponden a un intento de fortificar la presencia española en el país, a través de mejorar los métodos de explotación y las vías de entendimiento con la población nativa. Por ello muchas de las apreciaciones que hacen son severas, incluso implacables, y variados los aspectos que tocan, aunque con distinta profundidad: agricultura, comercio interno y exterior, industria, ganadería, demografía, política fiscal, monopolios del Estado, administración civil y militar, asuntos eclesiásticos, defensa y seguridad públicas, trabajos obligatorios, educación, autoridades indígenas, etc.

4 AGI, Estado, 47. Santiago de Salaberrias, Informe sobre la Isla de Panay. Manila, 14 de febrero de 1991 ,

5 Ibídem, Observaciones...

Tomo LIII, 2, 1996 
Es obvio que no se pueden comentar aquí todos ellos, por lo cual se ha hecho una selección y se han escogido los que, más que planes o proyectos, suponen un análisis de la realidad del país que a ellos les tocó vivir. Mi trabajo se centrará en las opiniones que dieron los autores sobre: la personalidad colectiva de los nativos; las formas de explotación colonial y su repercusión sobre la mayoría de la población y las causas que originaban lo que ellos llamaban "el atraso".

\section{La personalidad colectiva de los naturales}

No voy a entrar aquí en discusión sobre la conveniencia o los peligros de aceptar el principio mental de una personalidad colectiva, pero para un historiador es importante el que mucha gente de aquella época - y mucha de la nuestra - utilizaba ese tipo de ideas. Que el racismo se nutre de ellas es más que cierto, pero es igualmente obvio que esas opiniones sobre el conjunto de un pueblo, de una etnia o de una nación no son neutras ya que tienen consecuencias en muchos aspectos de la vida de las sociedades.

Todos nuestros autores se levantan contra la idea, ya extendida entonces, del malayo perezoso y lo hacen con una fuerza no exenta de indignación. Uno de ellos ${ }^{6}$ llega a señalar que la pereza es algo relativo y que no debía rechazarse al indígena porque careciera del temperamento vivo y violento de los españoles. El nativo, decía, trabajaba la tierra sin que nadie se lo ordenase. El cultivo del cacao, la batata o el maíz, "plantas nuevas introducidas después de la conquista", lo realizaban sin más estímulo que el comercio interno. Destacaba también las numerosas especies de arroz que cultivaban en llanos y montes. Donde no faltaba población, no se hallaban tierras incultas e incluso se laboraban los terrenos alejados de los pueblos. En los momentos en que la demanda crecía o se diversificaba, los campesinos se adaptaban a las nuevas circunstancias. Así, cuando en los últimos años se había presentado un período de hambre en las provincias meridionales de China, se extendieron en Filipinas las siembras de arroz, se abrieron nuevas tierras en Ilocos y todos fueron testigos de la diligencia de los nativos. El cultivo del azúcar aumentó el doble en la Pampanga por la demanda representada por las embarcaciones que llegaron de la India transportando géneros para la Compañía de Filipinas. Los nativos se aplicaban

$$
6 \text { Ídem. }
$$


a conseguir artículos que no se consumían en Manila sino que eran exportados a China: nido de pájaro, aletas de tiburón y balate (babosa marina comestible). Cuando la Compañía de Filipinas demandaba añil, los malayos lo cultivaban con empeño. El desconocido autor de Observaciones... concluía su alegato diciendo que "el trabajo falta más bien a la gente que la gente al trabajo".

Vértiz y Salaberrias no eran menos entusiastas en elogiar la laboriosidad, la inteligencia, la destreza y el ingenio de la gente filipina, capaces de imitar y mejorar cualquier cosa, que construían todas las embarcaciones, los templos y las casas de los eclesiásticos; eran magníficos marineros, agricultores y artesanos. Es decir, los tres reaccionaban contra the myth of the lazy native, ${ }^{7}$ aunque no hay que pensar que estos hombres pudieran ser paladines de una cruzada de reivindicación de los pueblos oprimidos. Probablemente sus ojos supieron ver mejor a los filipinos, pero su mentalidad no puede llegar a una crítica profunda del principio de la colonización y de la superioridad de la cultura europea, algo ya muy formado para finales del siglo XVIII, como se sabe, incluso entre los defensores de la pretendida bondad y pureza del bon sauvage. Ellos estaban convencidos del beneficio que los españoles podían hacer a los nativos, que precisaban una tutela para alcanzar la superación: "Uno de los efectos más notables de la conquista ha sido el rápido proceso de población, muy marcado en todas las provincias de la Isla de Luzón, debido al estado de mayor civilización que adquirieron los naturales". ${ }^{8}$

\section{Las formas de explotación colonial y su repercusión}

Sin embargo, denunciaban la situación que sufrían los nativos. Al igual que otras fuentes de la época, insistían en la pobreza que los afectaba, mayor que la que se daba en otras regiones del Imperio. Ligaban la pobreza de la mayoría de la población con el atraso y consideraban que sus causas se relacionaban con formas y abusos de la colonización. Presentaban al nativo filipino sometido a una serie de obligaciones que les causaban perjuicios:

- Frente al Estado, al que debían pagar un tributo y prestar servicios en trabajo.

7 Alatas, S. H.: The Myth of the Lazy Native. London, 1977.

8 Vértiz, Observaciones... 
- Frente a su propia comunidad, a la que rendían servicios en las Casas de Comunidad, las guardias de noche, puestos, despachos de los alcaldes mayores, etc.

- Frente a la Iglesia católica, realizando trabajos para la construcción y el mantenimiento de las parroquias y casas de los párrocos, así como diversas tareas a favor de éstos y de sus familias.

Las relaciones que se establecían entre estos tres niveles y la mayoría de los nativos conllevaban abusos que nuestros autores denunciaban, sin pretender desde luego que fueron los únicos en hacerlo.

En Filipinas, lo mismo que en las colonias americanas, entre los funcionarios más criticados estaban los alcaldes mayores. Se decía de ellos que empezaban a gobernar sus provincias sin preparación, con una gran ignorancia de lo que eran las obligaciones de su cargo. Se les acusaba igualmente de observar un comportamiento poco escrupuloso. ${ }^{9}$ Puesto que no tenían recursos económicos abundantes, aprovechaban su situación de autoridad para ejercer un comercio que perjudicaba a los nativos, ya que elevaban desproporcionadamente los precios cuando ellos vendían, los hacían bajar cuando compraban y efectuaban trampas en las medidas y en el cambio monetario. ${ }^{10}$

Aunque estos abusos eran conocidos de tiempo atrás porque se habían levantado muchas voces contra ellos, el Estado no llegaba a remediarlos porque no se hacían verdaderos juicios de residencia. ${ }^{11}$ Pero en lo referente a los alcaldes mayores se decía que no se realizaban con el debido rigor porque en las Islas Visayas los magistrados que podían encargarse de esta tarea debían desplazarse desde Manila y por lo tanto afrontar una larga y penosa navegación. Por eso delegaban la realización de estos procesos a los alcaldes mayores que iban a ser los sucesores de los enjuiciados (residenciados), por lo cual no les convenía castigar las vejaciones que ellos mismos iban a continuar. ${ }^{12}$ Incluso Salaberrias, que había sido alcalde mayor, aunque más moderado en sus críticas, no dejaba de subrayar la negligencia de sus colegas en el área de Antique, la cual, según su opinión, tenían descuidada desde 1764 en que se erigió en provincia. ${ }^{13}$

9 Observaciones...

10 Vértiz.

11 Proceso a los que tenían que someterse los funcionarios cuando terminaba el período de su cargo. Cunningham, Ch. H.: The Audiencia at the Spanish Colonies as Illustrated by the Audiencia of Manila. New York, 1971.

12 Vértiz.

13 Salaberrias. 
Es obvio que las opiniones que aquí se comentan han de ser filtradas pues no tienen por qué estar exentas de implicaciones tales como rivalidades o rencillas personales. Así el autor de Observaciones... se muestra muy ácido al criticar la labor realizada por el famoso gobernador general José de Basco y Vargas, quien había tenido roces con los magistrados y con el intendente general, ${ }^{14}$ aunque no dejaba de extender su visión a la política económica general de los jefes supremos de las Islas. Señalaba que los gobernantes se habían ocupado más del enriquecimiento de las cajas reales que del desarrollo de Filipinas y que en los escritos que emanaban del gobierno no se hallaban más que imposiciones y medidas imprudentes que debilitaban el amor del nativo hacia España.

El mismo autor decía que el establecimiento de nuevos impuestos llevado a cabo por Basco había sido un duro golpe para la pobreza del territorio. Detallaba algunas de estas cargas fiscales y opinaba que todo se había hecho demasiado rápidamente y en momento poco oportuno. No se habían atendido las circunstancias de tiempo ni de lugar, pues no siendo una zona conquistada sino de sujeción voluntaria, tenía derecho a exenciones por su pobreza. ${ }^{15}$ En ello se quebrantaron todas las reglas de la política, de la justicia y de la prudencia. ${ }^{16}$ Los efectos se sintieron inmediatamente en una subida de precios que afectó hasta los comestibles más básicos. Tales impuestos fueron más tarde suprimidos por orden del rey que desautorizó a Basco, pero el monopolio del tabaco implantado por este gobernador se mantenía y como se sabe duró un buen tiempo. ${ }^{17} \mathrm{El}$ autor de Observaciones... criticaba el estanco del tabaco por las siguientes razones:

- Haberse reducido el espacio dedicado a la siembra de esta planta, cuyo consumo estaba muy extendido entre los habitantes de Filipinas.

- La compra del producto a los agricultores se había efectuado a precios irrisorios.

- El monopolio no sirvió para abaratar los precios de venta al público sino que el tabaco siguió siendo caro.

- Se producía una pérdida de circulante en el país al salir la plata resultante de las ganancias para España: "La ganancia líquida que queda en

14 Díaz-Trechuelo, M. ${ }^{a}$ L.: "La Intendencia en Filipinas". Historia Mexicana, T. XVI, no 4, México, 1967, págs. 498-515; García de los Arcos, M. ${ }^{a}$ F.: La Intendencia en Filipinas, págs. 55-96.

15 Molina, A.M.: Historia de Filipinas. Madrid, 1984, T. I, págs. 33-94.

16 Observaciones...

17 Jesús, H. de: The Tobacco Monopoly in the Philippines, 1782-1882. New Haven, 1973; Pelzer, K.J.: "The Spanish Tobacco Monopoly in the Philippines, 1782-1883 and the Dutch Forced Cultivation System in Indonesia, 1834-1870”. Archipel, n. ${ }^{\circ}$ 8, París, 1974, págs. 147-153. 
la Tesorería de la renta pasa de trescientos mil pesos al año y nada vuelve a la masa circulante en las islas, ya que se remite a España íntegramente. Con una extracción tan considerable en un país que no tiene minas de plata, pues hasta ahora toda viene de la Nueva España, se puede calcular el período de tiempo suficiente para que no quede un solo peso en provincias y ya se comprende la pobreza y la miseria que resulta cuando se reduce el comercio de un país a trueque de géneros". ${ }^{18}$

- La represión del contrabando se había hecho con métodos rigurosos que habían causado horror.

- Por todo ello se habían levantado protestas ${ }^{19}$ y "de tantas injusticias como entonces padecieron los nativos les queda memoria para vengarse a su tiempo". ${ }^{20}$ Para cuando llegara ese momento, profetizaba, los daños serán atribuidos a los infieles (es decir a los que no eran cristianos ni estaban sometidos a las leyes españolas) para proceder a su destrucción y exterminio.

A finales del siglo XVIII perduraba en Filipinas uno de los elementos de la colonización española que mayor repulsa suscitaron en los nativos. Se trata de los repartimientos o trabajos obligatorios que en Filipinas se llamaron polos. Según las leyes, tales servicios no podían exigirse más que para las obras del Estado, pero incluso respetándose esta norma se denunciaban "las injusticias y perjuicios correspondientes" ${ }^{21}$ Los polos estatales que describen los autores son obras de fortificación de Manila, cortes de madera para la construcción naval, las cárceles de los pueblos y los bantayes o centinelas. Los perjuicios que resultaban eran múltiples:

- El hecho de que fueran voluntarios humillaba a los trabajadores.

- Estos debían desplazarse desde sus lugares de residencia habitual dejando temporalmente a sus familias y abandonando los sembrados.

- Para la tala de madera tenían que usar sus propios animales, los cuales se dañaban en las labores de arrastre.

- Los encargados de vigilar las tareas inventaban medios suplementarios para explotar en su beneficio a los polistas.

Ahora bien, en la realidad la obligación de prestar servicios de trabajo no se limitaba a las obras de interés público, sino que, según se decía, otras instancias exigían igualmente estas prestaciones a los nativos, los cua-

18 Observaciones...

19 Costa, H. de la: Asia and the Philippines. Manila, 1967, págs. 70-71.

20 Observaciones...

21 Ibídem. 
les debían realizarlos para las casas de los alcaldes mayores de los párrocos y para los principales o indígenas de posición social prominente.

Entre las autoridades nativas más criticadas estaban los cabezas de barangay. Considerados nobles o principales, eran poderosos personajes en las zonas rurales. Sus funciones básicas eran recolectar un cierto número de tributos y ocuparse de la distribución de los trabajos obligatorios. Los cabezas de barangay hacían que los mismos tributarios se convirtieran en sus criados a costa del tributo que pagaban por ellos; hacían que tuvieran que solicitarles un permiso para cultivar sus sementeras o para ausentarse; imponían multas de dinero y castigos de azotes, ${ }^{22}$ ocultaban tributos al tesoro, motivando que en el padrón oficial no aparecieran todos los tributarios, con lo cual ellos se embolsaban el importe de los que no figuraban en las listas; vejaban a los polistas y actuaban con nepotismo. ${ }^{23}$

De los tres autores, fue Vértiz el que hizo una elocuente denuncia de ciertas actividades de los párrocos y del desmesurado poder que las órdenes religiosas tenían en el país, algo bien conocido en la historia de Filipinas. El fugaz intendente de provincias fue una de las más decididas voces que se levantaron en la segunda mitad del siglo XVIII contra el predominio de los frailes en las zonas rurales. ${ }^{24}$ Los acusaba de:

- Maltratar a los feligreses nativos con castigos físicos.

- Reclamarles servicios de trabajo gratuito. A los hombres: pesca, marinería, servicios domésticos, ganadería, agricultura, corte de hierba, transportes, mensajería, construcción de embarcaciones, edificación y mantenimiento de casas e iglesias. A las mujeres: lavado de ropa, hilado, tejido, confección de ropa, suministro de leña y de agua. Según Vértiz todo esto era exigido a los más pobres, no a los principales, ni a sus hijos o parientes ni a los que se indultaban por dinero.

- También fue Vértiz uno de los más claros en culpar a los religiosos de un fenómeno que causaba molestia y estupor a muchos españoles de la época y que aún hoy provoca extrañeza a los que no son estudiosos de la historia de Filipinas: el hecho de que la lengua española no fuera hablada por la mayoría de los habitantes del país. ${ }^{25}$ El consideraba que una

22 Scott, W.H.: Cracks in the Parchment Curtain and Other Essays in Philippine History. Quezon City, 1982, págs. 158-163.

23 Vértiz, Salaberrias, Observaciones...

24 AGI, Ultramar, 682. El deán y Cabildo. Manila, 26 de enero de 1804; el conde de Tepa. Madrid, 8 de julio de 1778 .

25 AGI, Filipinas, 1006. Contestación que da el obispo de Cebú. Cebú, 14 de febrero de 1815. 
de las causas de ello era la falta de maestros que la enseñaran en las escuelas, pero que otra causa importante era que los religiosos querían jugar un papel de intermediarios entre los nativos y los funcionarios de la administración. Al impedir a los primeros que conocieran el español, cercenaban de hecho su libertad de acercarse a otros españoles que no fueran el cura del pueblo. Es evidente que esto iba en contra de las disposiciones de la Corona $^{26}$ y contra la política de aculturación que se había llevado a cabo en la mayoría de las colonias españolas. Todo ello no era sino una manifestación más del desdén con que las órdenes religiosas actuaban con respecto al poder central. Los frailes no obedecían las órdenes del rey, ni las del gobernador ni las de la Audiencia. Actuaban como jefes autónomos en los pueblos. ${ }^{27}$ En el escrito de Vértiz hay una reflexión que sorprende por su crudeza y es el reconocimiento de un fenómeno (también apuntado por el autor de Observaciones...) que no podía ser grato a los españoles: éstos no eran precisamente queridos por todos los filipinos. Tal constatación suponía una prueba de valentía y reflejaba una firme voluntad de ir al fondo de las cosas y utilizar la crítica para reconocer los problemas que había que resolver. Señalaba que el hecho de que los nativos no hablasen español creaba una barrera entre ellos y los españoles. Si tuvieran ambos grupos la misma lengua materna "no serían los españoles tan odiados en el país", gozarían de un mayor afecto por parte de la población y habría mayor comunicación entre unos y otros. Después de tan largo tiempo de presencia española y siendo ambos grupos vasallos del mismo rey no se entendían, lo cual perjudicaba el comercio, la convivencia y el proceso de asimilación cultural..$^{28}$

- Por los malos tratos que infligían a los feligreses, los frailes provocaban que muchos de ellos huyeran, al preferir abandonar sus casas y pueblos que soportar la situación.

La opinión adversa manifestada por Vértiz en cuanto a los párrocos religiosos no era compartida por el autor de Observaciones..., que consideraba que la distancia que guardaban los curas europeos con respecto a los nativos era conveniente para demostrar la superioridad de aquéllos y mantener el respeto. ${ }^{29}$

26 Blair, H. y J.A. Robinson: The Philippine Islands, Cleveland, 1903, XLV, pág. 221.

27 Le Gentil de la Galaissière: Voyage dans les mers de l'Inde. Paris, Imprimerie Royale, 1781, T. II, pág. 55.

28 Vértiz.

29 Observaciones.. 


\section{Las causas del atraso filipino}

Pese a la visión negativa que nuestros autores tenían sobre muchos aspectos, existía también en ellos la idea, compartida por otros, de que Filipinas poseía un potencial de riqueza natural y humana que podría ser mejor explotado para el engrandecimiento del país y su más fructífero aprovechamiento por parte de la metrópoli. Como en otros momentos de su historia, Filipinas generaba expectativas de un futuro promisorio. Obviamente no podían dejar de señalar que el país gozaba de una inmejorable situación estratégica que lo hacía eslabón importante en la cadena de comunicación entre Asia y América. La proximidad a China le permitía aumentar su población, industria y comercio, mientras que su distancia al continente asiático lo preservaba de las revoluciones que eran tan frecuentes en él. ${ }^{30}$ Algo interesante es que dos de los autores señalaban la conveniencia de hacer venir chinos a Filipinas como una medida para fomentar la economía y luchar contra la despoblación. ${ }^{31}$

La opinión favorable que tenían sobre los nativos hacía que resaltaran su buena disposición para diversas actividades productivas y para el comercio interno. Este podía ser aumentado al desarrollar los recursos que se pensaba que el país poseía en abundancia. Otra de las ventajas, muy mencionada también por otras fuentes, era la "fertilidad" del suelo, tan apropiado para el cultivo de plantas tropicales, la riqueza de sus recursos forestales y por lo tanto de madera para la construcción naval. ${ }^{32}$

Para reforzar su optimismo todos ellos comentaban una serie de artículos producidos en el país (algunos de los cuales ya eran comercializados con relativa amplitud) y que podrían facilitar a Filipinas ciertas ventajas de cara a un futuro desarrollo: arroz en numerosas variedades, cacao, trigo, tabaco, sibucao, azúcar, añil, pimienta, canela, algodón, abacá, coco, maderas, aceite, buri, borona, camotes, plátanos, cera, perlas, concha, balate, nido, carey, camarón, pescado, hierro, oro, cobre, brea, nervios, carne y cuero de venado, caballos, vacas, carneros, aves, carabaos, cerdos, tejidos de algodón y seda. ${ }^{33}$

Pero, pese al optimismo en cuanto al análisis de las perspectivas futuras, la realidad que reconocían era de atraso y exponían lo que considera-

30 Ibídem.

31 Vértiz, Observaciones...

32 Observaciones...

33 Ibídem, Vértiz, Salaberrias. 
ban sus causas. Ya se han comentado algunas, otras que se extraen de los escritos son:

- La diferencia demasiado marcada entre Manila y las provincias, de la cual se derivaba la escasa inversión en la agricultura y el poco desarrollo tecnológico de ella.- La posición de Manila (entendiendo por esto el complejo Manila-Tondo-Cavite) como entrepot internacional y capital de la colonia la hacía gozar de un papel predominante en la economía insular. Todo ello se debía a que la pequeña comunidad laica española se dedicaba casi exclusivamente al intercambio comercial entre Asia y América. Manila era vista como "la cabeza monstruosa de este cuerpo miserable". ${ }^{34}$ Justamente en este período se discutía en diversas instancias de la administración colonial la necesidad o la posibilidad de abolir el sistema del galeón transpacífico, aparte de las alternativas que suponían la Real Compañía de Filipinas y la apertura del puerto de Manila un poco después. ${ }^{35}$

Sin embargo, el autor de Observaciones... no se mostraba partidario de suprimir el régimen del galeón, y contestaba el argumento, utilizado por algunos, de que el comercio interno y la agricultura no serían florecientes mientras subsistiera el galeón de Acapulco y lo que él implicaba. Decía que los españoles (refiriéndose como españoles tanto a los europeos como a los criollos americanos, tal como se empleaba el término en aquella época) habían sido atraídos a Filipinas por el comercio transpacífico y si éste faltara lo más probable era que abandonasen el archipiélago. Decía que la dedicación al cultivo de la tierra no se podía improvisar y que cualquier cambio en el orden en que se había fundamentado una colonia había de ser muy meditado y lento para que no redundara en trastornos.

Pero Vértiz se quejaba de algo más: de la dirección que Manila asumía en ciertos aspectos de la economía filipina. Por ejemplo, en la fijación de precios, la cual afectaba negativamente a las mercancías que desde las provincias llegaban a la capital, donde a veces los productos resultaban más baratos que e sus mismos lugares de origen. ${ }^{36}$

- El drenaje de plata hacia China.- También en este punto de los confines de un Imperio se levantaban voces contra las consecuencias del tradicional déficit en el comercio entre Europa y Asia, aunque en este caso

34 Vértiz.

35 Díaz-Trechuelo, Ma L.:”Manila: Puerto Franco. El Comercio libre en la última década del siglo XVIII". 38 Congreso de Americanistas, Stuttgart-Munich, 1968, T. III, págs. 501-508.

36 Vértiz. 
se tratara de la plata americana. ${ }^{37} \mathrm{~A}$ este hecho negativo se le proponía un remedio: exportar algodón en rama de Filipinas a China, con lo cual se pensaba compensar el desequilibrio de la balanza comercial. ${ }^{38}$

- La violencia de los malayos musulmanes del sur contra los territorios situados bajo el gobierno español._ Los autores no dejan de hacer alguna pequeña referencia a otros focos de tensión social como las sublevaciones de chinos y malayos cristianos ${ }^{39}$ pero ninguno les otorga el rango de causas del atraso de las islas. Por el contrario, todos enfatizan en los graves inconvenientes que producían los ataques de los moros, considerados casi siempre piratas por las fuentes españolas. El espacio y el interés que dedican a ellos los tres escritos es grande, lo cual es lógico por tratarse de documentos que prestan una especial atención a la islas Visayas, región particularmente asolada por los ataques. Señalan no solamente que las incursiones de los moros eran periódicas y abundantes sino también que existían incluso establecientos moros temporales en algunos lugares: según Salaberrias, en el momento en que él escribía se encontraban asentamientos en cinco ríos de la isla de Negros, donde se juntaba la mayor parte de las escuadras que salían de Mindanao y Joló (Sulu) en los meses de junio y julio; Vértiz señalaba que había uno en Masbate donde los moros construían sus embarcaciones y reunían a los cautivos que iban capturando antes de llevarlos a Mindanao para su venta.

Las consecuencias eran graves y afectaban a los nativos más desfavorecidos. Entre ellas mencionan: saqueos y destrucción de bienes, lugares, viviendas y personas; reducción a la esclavitud de "muchos" habitantes que eran conducidos al sur y vendidos o empleados en diversas tareas por los captores; huida de otros muchos que, para escapar del peligro, se refugiaban en los montes o en las espesuras del interior de las islas; como resultado, había despoblación y algunas islas habían quedado desiertas, tal como ocurría con Burias, Sibuyan, Tablas, Bantoncillo, Sigmará, Cobrador y Maestre del campo; ${ }^{40}$ el clima de violencia que reinaba en el mar y perturbaba la navegación, pues hasta las embarcaciones del Estado eran atacadas por los moros.

37 Valdés Lakowsky, V.: De las minas al mar. Historia de la plata mexicana en Asia. 15651834. México, 1987; Boxer, C.R.: "Plata es sangre. Sidelights on the Drain of Spanish American Silver in the Far East. 1550-1700". Philippine Studies, T. XVIII, n 3, Manila, 1970, págs. 457-475.

38 Vértiz.

39 Observaciones.., Vértiz.

40 Ibídem.. 
Criticaban al gobierno de Manila por no haber sabido dar una solución política a un problema que tanto se prolongaba en el tiempo y que debería haber sido resuelto por un efectivo y duradero tratado de paz, ${ }^{41} \mathrm{o}$ con una más dura intervención militar ${ }^{42}$ que hiciera que los españoles pasaran a la ofensiva y llevaran la guerra al territorio enemigo.

- El exceso de poder en manos de los gobernadores generales.-Tal vez de los tres autores, el más crítico hacia el gobierno central de las islas fue el que escribió Observaciones... Para él los gobernadores generales de Filipinas, esos virreyes de facto, tenían demasiados recursos de poder, cosa que evidentemente ha de ser relativizada y puesta en cuestionamiento. Pero merece la pena señalar las dificultades que, según él, entorpecían el desempeño de los gobernadores:

a) Estos raramente eran gente conocedora del país. Hubo entre ellos ciertamente algunos que residían o habían residido en él, pero la mayoría eran enviados desde España sin que hubiera habido un previo contacto. Por lo tanto la información con que llegaban era escasa, limitada a algunos desórdenes que tenían que evitar y de los cuales no dependía en exclusiva el "atraso" de las islas. "Faltando generalmente un estudio tan preciso, la instrucción lenta que origina la experiencia llega, cuando se adquiere, al final de su mandato, en un momento en que se pierde ya todo el fruto puesto que el sucesor no se beneficia de ello por falta de comunicación".

b) Además estaban sobrecargados por la intensidad y la variedad de las labores propias de su cargo. "Los gobernadores puramente militares entran en un laberinto en el que se ven rodeados de negocios ajenos a su carrera. Las materias de guerra, marina, comercio, patronato, policía y real hacienda de veinticinco provincias originan un cúmulo de ocupaciones que les ofuscan la atención y les distraen de lo que interesa al adelantamiento de las islas. La pesadez con que todo se trata aumenta las ocupaciones, ateniéndose sólo a lo más urgente".

c) Los gobernadores no eran asistidos por un funcionariado suficiente. Solamente disponían de un secretario, mientras que eran necesarios varios para distribuir entre ellos los negocios.

d) Algunas leyes no se cumplían, por ejemplo las relativas a la distribución de los fondos de comunidades y las visitas de los oidores.

e) Los gobernadores se ocupaban demasiado de extender los límites de su poder. Según el autor de Observaciones... era una ambición común a

41 Observaciones... 
todos, que deseaban un gobierno de tipo militar y sentían repugnancia por las restricciones a su autoridad que pretendían absoluta. Por eso querían la extinción de la Audiencia y en su lugar el establecimiento de un gobierno fuerte con varios asesores entre quienes se distribuyeran las diversas materias, políticas, civiles y criminales. En ninguna parte de América, decía, había poder ni desorden igual que en Filipinas. Para él era evidente el peligro de confiar tanto poder a un hombre a seis mil leguas de distancia de la metrópoli.

Es evidente que estas aseveraciones no pueden ser tomadas al pie de la letra, ya que si bien es cierto que los gobernadores tuvieron roces y conflictos de jurisdicción con otras instancias, también lo es que algunas de ellas constituían en Filipinas un verdadero poder paralelo al del jefe supremo de las islas. Vértiz fue más analítico al completar el panorama de las estructuras de poder con su planteamiento del dominio ejercido por los religiosos párrocos en las zonas rurales, situación que el autor de Observaciones... reconocía pero sin tomarla en cuenta, ya que presentaba al poder central casi aislado de presiones e intereses contrapuestos.

Todo documento histórico ha de ser sometido a crítica y a cotejación con otras fuentes de información, pero, cumpliéndose con estos requisitos, se puede concluir que los tres escritos que han sido parcialmente presentados aquí pueden ser de utilidad en la investigación por la variedad de los temas que tratan, así como por el carácter crítico y propositivo que enriquece sus puntos de vista. 